\title{
DINAMIKA “OCCUPATIONS" DALAM PERSPEKTIF IBU-IBU YANG MERAWAT ANAK DENGAN AUTISME DAN DAMPAKNYA TERHADAP KUALITAS HIDUP (LIFE QUALITY) SEHARI-HARI
}

\author{
Eko Sumaryanto ${ }^{* 1}$,Gandes Mutiara Aziz ${ }^{2}$ \\ Poltekkes Kemenkes Surakarta Jurusan Okupasi Terapi
}

\begin{abstract}
Background: As the challenges arise in raising children with autism, mothers experience changes with their occupations and also on how they define them. This later alters the overall wellbeing both psychosocially and physically as changing on health status determines the life quality. Parents, particularly mothers with autistic children may encounter dynamic to their life quality as they discover adjustment on meanings of occupations while fostering their children. Research purposes of the study are to discover and to explore the mothers interpretations on their current occupations related to their role as main caregivers of their autistic children. Methods: This is a qualitative study with phenomology approach to discover and to explore the meaning of occupations and the dynamic of perceived-life quality as the meanings of occupations might shifting along the nurturing processes. This study had selected four people as research participants. The data were then collected through in-depth interviews and followed with thematic analysis. Results: Based on the analysis process, this study highlighted three main themes as follow, the general changes in life, the values of roles, and the perceived-life quality. Mothers who foster their autistic children had reported various changes in their daily occupations and how they perceived the meanings of these occupations as the diagnoses have altered the familial hierarchy within their domestic environments; this later also has significant impacts on their perceived-quality of life while fulfilling their role as the main house keepers. Thus, all these changes enforce the mothers to always strive on their best as this effort will eventually deliver positive meanings, such as self-confidence, greater responsibilities related to the roles as a mother and the possitive supports received from their support systems. Conclusion: The respondents reported the overwhelming perceived-satisfactions when talking about their quality of life. This is the result from personal beliefs over the ability to devote their life for the children and the family despite the perceptions that they are still unable to enjoy their general life ideally.
\end{abstract}

Keywords: Meaning Of Occupations, Life Quality, Parenting, Autism

\section{PENDAHULUAN}

Menjalani peran sebagai ibu dapat membuat individu yang bersangkutan mengalami berbagai proses perubahan yang melibatkan pemaknaan berbagai occupations dalam hidupnya (Horne, Earle, \& Sarah, 2004), dimana occupations dalam studi ini dimaknai sebagai aktivitas bertujuan yang dilakukan oleh setiap manusia berdasarkan kebutuhan diri serta adanya pengaruh konteks budaya dan lingkungan tempat tinggalnya (Early, 2009; Horne, Earle, \& Sarah, 2004). Hal ini senada dengan 
fenomena yang terjadi diantara para orang tua khususnya para ibu yang merawat anak-anak dengan Autism Spectrum Disorder (ASD). Anak ASD memiliki masalah dalam interaksi sosial, komunikasi, dan masalah perilaku (American Psychiatric Association, 2017), serta sering dikaitkan dengan adanya ketidakmatangan perkembangan pada kemampuan refleks dan sensorimotor (Daulay, 2017) yang dapat menghambat mereka dalam melakukan aktivitas dalam kehidupan sehari-hari, seperti kegiatan perawatan diri, kegiatan produktifitas seperti sekolah dan bermain, dan kegiatan leisure (Early, 2009; DeGrace, 2004; McGuire, Crowe, Law, \& VanLeit, 2004), kondisi ini mengharuskan ibu yang merawat anak ASD untuk terlibat penuh pada perawatan fisik, dan atau bertanggung jawab untuk meluangkan lebih banyak waktu untuk terlibat dalam proses intervensi yang diberikan oleh para profesional medis yang diperlukan untuk bekerja dengan anak-anak ASD ini (McGuire, Crowe, Law, \& VanLeit, 2004). Lebih lanjut Tung (2014) menyatakan bahwa ibu-ibu yang merawat anak ASD seringkali memiliki masalah psikososial, seperti stress, depresi, menurunnya kesehatan fisik dan health related quality of life. Perubahan kualitas hidup merupakan dampak langsung dari bagaimana para ibu tersebut memaknai occupations mereka selama menjalani peran sebagai ibu yang merawat anak dengan ASD (Bar, Forwell, \& Backman, 2016; Esdaile, 2010). Makna occupations tersebut dapat bersifat subjektif, baik bermakna positif maupun negatif yang kemudian berkontribusi dalam kesejahteraan hidup individu yang bersangkutan (Bar, Forwell, \& Backman, 2016), serta keberlangsungan hidup mereka dalam menjalani perannya sebagai ibu yang memiliki anak ASD. Hal ini merupakan isu tersendiri dalam dinamika keluarga, yang dapat mempengaruhi perkembangan anak ASD secara langsung maupun kualitas hidup ibu yang merawat anak-anak tersebut. Penelitian ini bertujuan untuk mendalami fenomena terkait pemaknaan okupasi dan level kualitas hidup yang terjadi pada para ibu yang memiliki anak dengan ASD dan sedang menjalani proses terapi di Klinik ASA Club Jakarta. Berangkat dari observasi sehari-hari peneliti yang melihat bahwa anak ASD yang menjalani terapi di klinik ASA mengalami berbagai macam ketidakstabilan dalam perkembanganya dan hal tersebut kemudian berdampak pada pemaknaan dan kualitas hidup ibuibu yang mengasuh mereka. Peneliti melihat bahwa hal ini ada kaitannya dengan bagaimana peran seorang ibu yang memberikan andil cukup besar dalam proses pengasuhan anak ASD, sehingga peneliti ingin mengetahui lebih dalam bagaimana dinamika para ibu yag memiliki anak ASD di Klinik ASA dalam memaknai occupations mereka dapat memberikan dampak terhadap kualitas hidup para ibu-ibu tersebut.

\section{METODE PENELITIAN}

Strategi yang digunakan oleh peneliti untuk mendapatkan informasi berkaitan dengan tema yang disasar adalah dengan menggunakan desain kualitatif fenomenologi. Dalam penelitian ini peneliti tidak hanya ingin menemukan pola atau kesamaan dari pengalaman manusia (Thorne, 2000), namun peneliti juga ingin menggali dan memahami lebih dalam apa dan bagaimana makna occupation pada ibu-ibu yang merawat anak ASD dan apakah kemudian 
pemaknaan tersebut mempengaruhi kualitas hidup sehari-hari hingga pada akhirnya mereka mampu bertahan dan menjalaninya kehidupan secara optimal. Penelitian ini dilakukan di Klinik ASA Club Jakarta pada kurun Tahun 2018. Partisipan dalam penelitian ini diambil dengan teknik purposive sampling, dimana partisipan diambil dengan sengaja dengan harapan dapat memberikan informasi yang dibutuhkan dengan keakuratan yang optimal karena karakteristik sampel tersebut merupakan sampel-sampel yang paling relevan dan kaya akan data sesuai dengan topik penelitian yang sedang dilakukan (Yin, 2016). Partisipan merupakan para ibu yang berperan sebagai sebagai pengasuh utama anak-anak ASD di Klinik ASA Club Jakarta, telah merawat anak ASD selama satu tahun atau lebih, usia anak ASD antara tiga hingga lima belas tahun dan bersedia ikut andil dalam penelitian ini melalui penandatanganan lemabrlembar inform consents yang telah terlebih dahulu disiapkan oleh peneliti. Dalam penelitian ini peneliti melakukan wawancara mendalam (in-depth interviews), obervasi dan menggunakan materi audio visual berupa foto, videotapes dan segala jenis suara atau bunyi yang memuat data-data yang dibutuhkan. Data yang didapatkan dianalisis melalui proses koding degan terlebih dahulu membuat tema-tema atau kategori. Hasil penelitian kemudian diuji keabsahanya melalui proses triangulation, member checking, dan peer debriefing.

\section{HASIL PENELITIAN}

Penelitian dilakukan di Klinik ASA Club Jakarta pada tanggal 21 April - 20
Mei 2018, dengan melibatkan sebanyak empat partisipan. Usia partisipan bervariasi antara tiga puluh hingga lima puluh tahun dan berjenis kelamin perempuan. Pendidikan terakhir partisipan bervariasi antara SMA sampai dengan Sarjana. Semua partisipan bersatus menikah. Partisipan yang ikut andil dalam penelitian ini sebagian besar merupakan ibu rumah tangga, dan satu diantaranya bekerja full time. Partisipan mayoritas beragama Islam dan satu diantaranya beragama Kristen. Usia anak ASD yang diasuh berusia antara delapan hingga lima belas tahun. Anak-anak tersebut dipastikan telah mendapatkan diagnosis ASD telah dengan rentang kisaran usia dari tiga hingga empat tahun. Partisipan rata- rata memiliki tiga orang anak dan satu partisipan memiliki dua orang anak termasuk didalamnya adalah anak ASD yang diasuh.

Penelitian ini menghasilkan tiga tema utama yaitu, Perubahan Hidup, Makna Peran Okupasional, dan Kepuasaan Menjalani Peran, dimana perubahan hidup merupakan perubahan kehidupan mulai dari perubahan pemaknaan occupations dan sistem keluarga yang kemudian dapat mengubah kualitas hidup para responden. Perubahan dalam hidup ibu-ibu yang merawat anakanak ASD tersebut memberikan dampak bagaimana para responden kemudian memaknai perannya sebagai ibu. Makna tersebut kemudian memberikan pengaruh terhadap kepuasan para responden dalam menjalani peran sebagai ibu yang merawat anak dengan ASD meliputi segala tantangan, pencapaian dan harapan ibu selama merawat anak ASD. 
Tabel 1. Tema dan Sub-Tema

\begin{tabular}{ll}
\hline Tema & \multicolumn{1}{c}{ Sub Tema } \\
\hline Perubahan Hidup & 1. Perubahan pada pemaknaan \\
occupations
\end{tabular}

Kepuasan dalam Menjalani Peran
Okupasional

\section{Perubahan Hidup}

Tema pertama yakni "Perubahan Hidup“, dalam tema ini terdapat tiga buah sub tema antara lain perubahan pemaknaan terhadap occupations yang dijalani, perubahan pada tatanan keluarga saat ini, perubahan pada kualitas hidup.

Perubahan pemaknaan terhadap occupations terjadi ketika responden mengalami perubahan dalam melakukan occupations-nya sebagai seorang ibu yang merawat ASD. Occupations ibu mengalami perubahan antara sebelum memiliki anak ASD dan setelah memiliki anak ASD, seperti mempersiapkan kebutuhan anak untuk sekolah baik anak ASD maupun anak lainnya, kemudian mengantar anak ASD ke sekolah, ke klub renang, mengantar anak untuk proses terapi, perubahan produktivitas sampai dengan perubahan aktivitas leisure para responden itu sendiri.

“...itu kan udah sampai kita pun berubah polanya itu baru perubahan itu ada... Ya pola makan. Pola hidup tuh berarti saya, orang tuanya harus prepare makanan tuh dari subuh gitu kan.” (LH)

Perubahan pada tatanan keluarga merupakan perubahan yang terjadi pada
1. Tantangan yang dihadapi

2. Pencapaian

3. Harapan sistem dalam keluarga anak ASD, dimana mengasuh anak yang memiliki ASD dapat menimbulkan konflik hubungan orang tua serta saudara kandung dari anak ASD tersebut.

"...ya karena kan udah habis ke dia kan pas ke anak ini udah capek kitanya karena semua dipegang sendiri...” (LH)

"...dia kan selalu obsesinya dia tuh kepengin jadi anak tunggal gitu hahaha 'aku pengin pergi sama ayah sama bunda tapi tanpa anak A' gitu hahaha 'iya aku kepinginya semua perhatianya ke aku' kaya gitu-gitu." (CN)

Perubahan pada kualitas hidup terjadi akibat perubahan occupations maupun adanya perubahan dalam dinamika keluarga, kualitas hidup ibu yang merawat anak ASD pun ikut berubah. Perubahan emosional, psikis, fisik serta menikmati aktivitas waktu luang mengalami perubahan sehingga kualitas hidup dan bagaimana ibu menikmati hidupnya bergantung pada perkembangan anak ASD.

"Masih belum kalau bisa menikmati hidup mah kalau pergi gak pake beban mikir aduh si An.S gimana hahaha jadi kalau disuruh pergi-pergi yang ada tuh pasti 
pikiran tuh anak-anak gitu tuh.” (LH).

\section{Pemaknaan Peran Okupasional}

Tema kedua adalah "Makna Peran", dalam tema ini terdapat empat sub tema yaitu makna kepercayaan, makna menjalani tugas, makna yang didapatkan, strategi menghadapi masalah dan dukungan dari lingkungan.

Makna kepercayaan merupakan makna dari nilai-nilai yang diyakini pada responden baik keyakinan spiritual maupun keyakinan dari dalam diri responden sendiri sehingga mereka mampu bertahan untuk terus melakukan perannya sebagai ibu yang memiliki anak ASD. Beberapa partisipan menyatakan bahwa memiliki anak ASD merupakan amanah dan ujian dari Tuhan sehingga mereka perlu selalu memberikan yang terbaik untuk anak-anak mereka dan pasrtisipan lain memaknainya dengan motto hidupnya bahwa kehidupan merupakan pelayanan yang ia berikan untuk melayani keluarga dengan sebaikbaiknya.

“...saya sih sama aja ya maksudnya kan anak itu kan titipan (Tuhan) kan mau dia ABK atau non ABK sama sih semuanya titipan , amanah, kita harus bisa apa ngedidik dia dengan sebaik-baiknya kan membekali dia kaya gitu." (CN)

Makna menjalani tugas merupakan makna yang berhubungan terhadap peranya sebagai seorang ibu. Para responden memaknai hal tersebut dengan bagaimana ia berdedikasi memberikan yang terbaik, bertanggung jawab suka ataupun tidak suka terhadap peranya sebagai ibu yang memiliki anak ASD, maupun berkorban dan berjuang untuk mencapai target yang diinginkan.

"..saya cuma berfikir anak-anak ini adalah geerasi kita $\mathrm{hmm}$ jadi tanggung jawabnya sebagai orangtua selama hidup tuh pasti melayani keluarga kan nah itu yang kita fokus disitu...... Sekarang jadi beban bagi saya $\mathrm{hmm}$ ya itu sudah resiko sebagai orang tua, jadi tanggung jawab.." (LH) Makna yang didapatkan merupakan kebutuhan yang terpenuhi sebagai seorang ibu dalam merasakan cinta, kasih sayang, kepuasan batin, mewujudkan rasa senang dan rasa bersyukur. Partisipan mendeskripsikan hal-hal penting dan positif yang mereka dapatkan dari melakukan perannya sebagai seorang ibu yang merawat anak ASD.

"tapi saya pikir saya malah jadi bersyukur juga, maksudnya bukan jadi saya hah jadi gak bisa me time, tapi saya malah bersyukur malah bagus sih jadi saya gak keluyuran tuh saya pikir malah gitu." $(\mathrm{CN})$

“..tapi akhirnya saya disitu belajar ikhlas pertama, ikhlas itu penting untuk punya anak-anak ABK ya..ikhlas dan sabar, dari situ saya baru oiya kalau kita jalanin dengan ikhlas sabar kita ga akan capek" (DA)

Strategi yang digunakan untuk menghadapi dan mengatasi masalah serta dukungan dari pihak lain merupakan bentuk strategi yang dilakukan para responden untuk memodifikasi segala hambatan yang dialami serta bentuk dukungan yang berasal dari eksternal sehingga responden mampu bertahan melakukan peranya sebagai seorang ibu. Beberapa partisipan menyatakan bahwa dengan memandang sesuatu secara positif dan menerima identitasnya sebagai seorang ibu, maka seorang ibu yang memiliki anak ASD dapat memberikan dorongan pada dirinya sendiri (selfsugestion) untuk selalu berupaya menjadi ibu yang terbaik bagi anak-anaknya.

"Pokoknya buang anggapan kalau anak itu 
tuh special needs gitu. Emang itu anak special needs kita harus terima itu tapi terus hal itu dijadikan ah yasudahlah gituloh pasrah dengan keadaan gitu, jadi harus tetap semangat gitu bahwa supaya dia bisa kok seperti anak-anak yang lain gitu bisa mandiri bisa ini gitu" (IP)

\section{Kepuasan dalam Menjalani Peran Okupasional}

Tema ketiga adalah “ Kepuasan Peran Okupasional“" dalam tema ini terdapat tiga sub tema lagi yakni tantangan yang dihadapi, pencapaian, dan harapan.

Tantangan yang dihadapi merupakan tantangan yang harus diselesaikan oleh para responden dalam merawat anak ASD, hasil dari melewati "tantangan" inilah yang nantinya dapat mempengaruhi kepuasan diri terhadap perannya sebagai ibu secara umum.

"dari proses dia anak-anak sampai sekarang kan alhamdulillah sudah lewat kan problemnya beda lagi. Nah itu sekarang yang lagi dijalanin adalah pubertas. Itu susahnya lain lagi dibandingkan masa anak-anak, dan ini bener-bener butuh apa ekstra kesabaran kalau saya bilang dibanding yang kemarin." (IP)

Pencapaian merupakan pencapaian yang didapatkan selama menjalani peranya sebagai ibu yang merawat ASD dan tidak terpenuhinya kebutuhan pada ibu. Pencapaian maupun hal yang belum terpenuhi yang dirasakan ibu selama merawat anak ASD berdampak pada kepuasan dalam kemampuanya merawat ASD.

"Makanya itu dibilang gak pernah puas ya karena itu kondisi-kondisi anak seperti itu. Terus juga anak yang lain, merasa gak puas kenapa gregetaannn. Udah tahu adiknya kaya gini gitu tuh bukanya kasih contoh yang baik gitu kan...... Puas itu kalau mereka itu anak-anak itu memahami satu sama lain, itu saya baru puas.” (LH)

Harapan merupakan ekspektasi atau apa yang dinginkan oleh responden terhadap diri mereka sendiri, anak mereka yang autistik, keluarga maupun lingkungan yang mampu mempengaruhi kepuasan terhadap perannya sebagai ibu yang merawat anak ASD.

"saya bisa menyelesikan hmm apa yang saya sudah ditargetin sesuai waktu..... Misalnya An. S tuh harus nentuin arahannya kemana itu sebelum saya tibatiba gak ada atau masalah gak bisa megang lagi atau gimana" (LH)

\section{PEMBAHASAN}

Merawat anak ASD membawa perubahan dalam hidup para responden. Penelitian ini menemukan bahwa ibu yang merawat anak ASD mengalami perubahan pada occupations mereka sebagai seorang $\mathrm{ibu}$, perubahan pada tatanan keluarga, serta perubahan pada kualitas hidup. Partisipan mengalami perubahan pada produktivitas, leisure, serta gaya hidup mereka antara sebelum memiliki anak ASD dengan saat mereka menjalani perannya sebagai ibu yang merawat anak ASD. Partisipan memilih untuk berhenti bekerja maupun memilih bekerja freelance sehingga dapat fokus menangani anak ASD, hal ini sesuai dalam penelitian Grasu (2015) bahwa ibu atau orang tua akan memilih berhenti dari pekerjaan mereka dan mendedikasikan diri untuk merawat anak mereka. Perubahan pada tatanan keluarga terjadi pada keluargakeluarga yang memiliki anak ASD. Partisipan menyatakan bahwa mereka seringkali menangani anak ASD sendiri karena kurang kooperatifnya suami. 
Penelitian Ilias, Liaw, Cornish, Park, \& Golden (2016) menyatakan hal yang sama bahwa ibu yang memiliki anak ASD hampir setiap waktu menjadi pengasuh utama bagi anak ASD sebagai akibat dari minimnya peran ayah dalam pengasuhan anak. Partisipan juga mengalami kelelahan dalam menjalani peranya namun hal ini tidak menjadi kendala yang berarti dalam kesehatan fisik mereka. Hal ini didukung oleh temuan Tung (2014) yang menyatakan bahwa para ibu yang memiliki anak dengan disabilitas mengalami penurunan kesehatan fisik dan kualitas hidup. Partisipan menyatakan mengalami perubahan pada occupations dan tatanan keluarga dan dengan segala perubahan tersebut partisipan menyatakan bahwa saat ini sudah lebih mampu menikmati hidup dibandingkan saat pertama kali mengetahui kondisi anak karena perkembangan anak yang semakin baik. Namun partisipan belum dapat menikmati hidup dengan sempurna akibat perasaan-perasaan negatif yang seringkali muncul selama menjalani peranya sebagai ibu yang merawat anak ASD.

Akibat adaya perubahan pada hidup mereka menyebabkan para responden menyusun pemahaman subyektif tersendiri dalam memaknai peran yang dijalaninya sebagai ibu yang merawat anak ASD. Makna occupations ibu bervariasi tergantung situasi dalam kehidupan mereka, bagi ibu yang merawat anak ASD makna yang berbeda dapat muncul secara beragam. Partisipan menyatakan menjadi seorang ibu yang memiliki anak ASD memberikan nilai tertentu sehingga menjadikan mereka selalu berupaya untuk bertahan dalam menjalani perannya sebagai ibu yang memiliki hambatan lebih besar dibandingkan ibu pada umumnya. Hal ini sejalan dengan temuan dari penelitian Bar, Forwell, \& Backman (2016) dimana ibu menggambarkan peran merawat anak dengan disabilitas sebagai peran yang paling berarti. Ibu-ibu tersebut menyatakan bahwa tugas dan rasa tanggung jawab atas peran mereka dalam mengasuh lebih diutamakan dibandingkan peran lainnya saat ini.

Makna yang digambarkan para partisipan sebagai ibu yang merawat anak ASD kemudian mempengaruhi bagaimana kepuasaan yang dirasakan ibu kaitannya dengan kemampuan mereka menjalani peran sebagai ibu dalam keluarga anak ASD. Kepuasan menjadi seorang ibu yang merawat ASD berhubungan dengan tantangan, pencapaian serta ekspektasi selama menjalani perannya sebagai ibu. Temuan ini selaras dengan penelitian Kang, Choi, \& Ju (2016) yang menyebutkan bahwa ibu-ibu yang memiliki anak ASD merasakan kepuasan dan bersyukur atas perubahan sekecil apapun yang terjadi pada anaknya, dimana hal ini kemudian membangun harapan untuk masa depan anak-anak mereka. Partisipan dalam penelitian ini merasakan kehidupan yang berarti apabila mereka mencurahkan hidupnya untuk melayani keluarga dan anak-anak mereka. Namun ironisnya, disaat yang bersamaan partisipan mengungkapkan jika mereka belum cukup bisa merasakan kepuasan terhadap peran mereka sebagai ibu karena belum mampu memberikan pelayanan dan menjadi ibu yang baik untuk anak-anak dan keluarganya.

\section{KESIMPULAN DAN SARAN}

Temuan-temuan yang diperoleh dalam penelitian ini menjawab masalah yang melatarbelakangi dilakukannya studi ini, dimana salah satunya menyatakan 
bahwa ibu yang merawat anak ASD dalam kurun waktu satu tahun atau lebih, merasakan perubahan dalam kehidupanya seperti perubahan ritme dan kebiasaan dalam melakukan occupations (habits) serta bagaimana mereka memaknai occupations tersebut (meanings), tatanan dalam sistem keluarga serta kualitas hidup mereka secara keseluruhan. Perubahan yang terjadi memberikan makna tersendiri bagi para responden, dimana mereka menemukan makna lebih berkaitan keyakinan dalam diri, rasa tanggung jawab sebagai seorang ibu dalam keluarga yang memiliki anak ASD, serta dukungan yang didapatkan dari support systems mereka sehingga muncul dorongan dalam diri para responden untuk kemudian selalu berupaya menjalani perannya sebaik mungkin. Ibu merasakan kepuasan (lifesatisfaction) apabila dapat mencurahkan hidupnya untuk anak dan keluarga meskipun merasa belum dapat menikmati hidup dengan sempurna.

Berdasarkan pemaknaan occupations ibu tersebut, okupasi terapis dapat mengaplikasikan pendekatan berbasis kognitif dalam membangun pemahaman serta persepsi baru mengenai pentingnya peran ibu maupun keluarga dalam pendampingan tumbuh kembang anak-anak dengan diagnosis ASD.

Melalui pendekatan berbasis kognitif tersebut, okupasi terapis juga dapat memberikan training dan konseling terkait peran baru yang dihadapi oleh ibu serta keluarga dengan anak-anak ASD, salah satunya dapat dengan mempersiapkan secara fisik maupun psikis ibu maupun anggota lainnya dalam menjalani tugastugas baru yang akan dihadapi, melakukan training cara melakukan pendampingan proses treatments anak-anak ASD saat di rumah (home programs), memberikan dukungan psikis pada orangtua serta keluarga agar menghindari adanya tekanan psikis maupun emosional semaksimal mungkin. Selain itu, okupasi terapis dapat memberikan feedbacks setelah dilakukannya sesi terapi dan juga mengadakan evaluasi terkait perkembangan anak termasuk di dalamnya hal-hal yang menjadi isu dalam keluarga dan pengasuhan anak-anak ASD, seperti menganalisis perkembangan yang terjadi dan tantangan yang masih menjadi masalah pada anak ASD, sehingga dinamika keluarga dan perkembangan anak pun akan tetap stabil.

\section{DAFTAR RUJUKAN}

Adak, B., \& Halder, S. 2017. Systematic Review on Prevalence for Autism Spectrum Disorder with Respect to Gender and Socio-Economic Status. Journal of Mental Disorders and Treatment,03(01). doi:10.4172/2471-271x.1000133

Al-Abbady, K., Hessian, H. Y., \& Alaam, M. W. 2017. Prevalence, Trend, Determinants and Prediction of Autism Spectrum Disorders among Dubai Population, Diagnostic Approach and Management Contexts. Pediatrics \& Health Research,2(2). doi:10.21767/25742817.100016

Arikunto, S. 1992. Prosedur penelitian: Suatu pendekatan praktik. Jakarta: Rineka Cipta.

Bar, M., \& Jarus, T. 2015. The Effect of Engagement in Everyday Occupations, Role Overload and Social Support on Health and Life Satisfaction among Mothers. International Journal of Environmental Research and Public 
Health,12(6), 6045-6065. doi:10.3390/ijerph120606045

Bar, M. A., Forwell, S., \& Backman, C. L. 2016. Ascribing Meaning to Occupation. OTJR: Occupation, Participation and Health,36(3), 148-158. doi:10.1177/1539449216652622

Belmonte, M. K. 2004. Autism and Abnormal Development of Brain Connectivity. Journal of Neuroscience,24(42), 9228-9231. doi:10.1523/jneurosci.3340-04.2004

Costanza, R., Fisher, B., Ali, S., Beer, C., Bond, L., Boumans, R., . . . Snapp, R. 2007. Quality of life: An approach integrating opportunities, human needs, and subjective wellbeing. Ecological Economics,61(23), 267-276. doi:10.1016/j.ecolecon.2006.02.023

Cresswell, J. W. 2014. Penelitian Kualitatif \& Desain Riset: Memilih diantara lima pendekatan (edisi terjemahan Bahasa Indonesia). Jakarta: Pustaka Pelajar.

Dardas, L. A., \& Ahmad, M. M. 2014. Quality of life among parents of children with autistic disorder: A sample from the Arab world. Research in Developmental Disabilities,35(2), 278-287. doi:10.1016/j.ridd.2013.10.029

Daulay, N. 2017. Struktur Otak dan Keberfungsiannya pada Anak dengan Gangguan Spektrum Autis: Kajian Neuropsikologi. Buletin Psikologi,25(1). doi:10.22146/buletinpsikologi.2516 3

Degrace, B. W. 2004. The Everyday Occupation of Families With Children With Autism. American Journal of Occupational
Therapy,58(5), doi:10.5014/ajot.58.5.543

Diagnostic and statistical manual of mental disorders: DSM-5. (2017). Arlington, VA: American Psychiatric Association.

Early, M. B. 2009. Mental health concepts and techniques for the occupational therapy assistant. Philadelphia: Wolters Kluwer Health/Lippincott Williams \& Wilkins.

Esdaile, S. A. 2010. A focus on mothers, their children with special needs and other caregivers. Australian Occupational Therapy Journal,4l(1), 3-8. doi:10.1111/j.14401630.1994.tb01805.x

Grasu, M. 2015. Challenges in Families with A Child with Autism Spectrum Disorder[PDF]. Brasov: Bulletin of the Transilvania University of Braşov.

Gray, D. E. 2002. Ten years on: A longitudinal study of families of children with autism. Journal of Intellectual \& Developmental Disability,27(3), 215-222. doi:10.1080/1366825021000008639

Guetterman, T. C. 2015. Descriptions of Sampling Practices within Five Approaches to Qualitative Research in Education and the Health Sciences. Retrieved June 13, 2019, from http://www.qualitativeresearch.net/index.php/fqs/article/vi ew/2290

Harper, A., Dyches, T. T., Harper, J., Roper, S. O., \& South, M. (2013). Respite Care, Marital Quality, and Stress in Parents of Children with Autism Spectrum Disorders. Journal of Autism and Developmental Disorders,43(11), 
2604-2616. doi:10.1007/s10803013-1812-0

Hoogsteen, L., \& Woodgate, R. L. 2013. Centering Autism Within the Family: A Qualitative Approach to Autism and the Family. Journal of Pediatric Nursing,28(2), 135-140. doi:10.1016/j.pedn.2012.06.002

Horne, J., Corr, S., \& Earle, S. 2005. Becoming a Mother: Occupational Change in First Time Motherhood. Journal of Occupational Science,12(3), 176183.

doi:10.1080/14427591.2005.968656 1

Ilias, K., Liaw, J. H., Cornish, K., Park, M. S., \& Golden, K. J. 2016. Wellbeing of mothers of children with "A-U-T-I-S-M" in Malaysia: An interpretative phenomenological analysis study. Journal of Intellectual \& Developmental Disability,42(1), 74-89. doi:10.3109/13668250.2016.119665 7

Indonesia, K. K. 2009. Undang-Undang Kesehatan Republik Indonesia No. 36 tahun 2009. Retrieved June 13, 2019 , from http://www.jkn.kemkes.go.id/unduh an.php? page $=3$

Indrawati, S. M., Herlina, \& Misbach, I. 2007. Teori Observasi. Bandung: Fakultas Ilmu Pendidikan, Universitas Pendidikan Indonesia.

Jacob, S. A., \& Furgerson, S. P. 2012. Writing Interview Protocols and Conducting Interviews: Tips for Students New to the Field of Qualitative Research. The Qualitative Report, 17(42), 1-10. Retrieved from https://nsuworks.nova.edu/tqr/vol17/ iss $42 / 3$

Kang, G., Choi, C., \& Ju, S. 2016. Parenting Experience of Mothers with Children with Autism Spectrum Disorder: An Analysis of the Mothers' Diaries. Indian Journal of Science and Technology,9(20). doi:10.17485/ijst/2016/v9i20/94698

Kedley, F., Valeo, A., \& Berman, R. C. 2009. Somali-Canadian Mothers Experiences in Parenting a Child with Autism Spectrum Disorder. Journal of Association for Reasearch on Mothering, 211-223 Volume 11 No 1.

Koerber, A., \& Mcmichael, L. 2008. Qualitative Sampling Methods. Journal of Business and Technical Communication,22(4), 454-473. doi:10.1177/1050651908320362

Labola, Y. A. 2017, June 25. Data Anak Autisme Belum Akurat? Retrieved June 13, 2019, from https://www.kompasiana.com/yos08 /anak-autisme-

tersisih_58eb4717af7a61ec1378f3e7 Lambrechts, G., Leeuwen, K. V., Boonen, H., Maes, B., \& Noens, I. 2011. Parenting behaviour among parents of children with autism spectrum disorder. Research in Autism Spectrum Disorders,5(3), 11431152. doi:10.1016/j.rasd.2010.12.011

Leclair, L. L. 2010. Re-Examining Concepts of Occupation and Occupation-Based Models: Occupational Therapy and Community

Development. Canadian Journal of Occupational Therapy,77(1), 15-21. doi:10.2182/cjot.2010.77.1.3 
Marshall, C., \& Miles, M. B. 2014. Designing qualitative research. Thousand Oaks, CA: Sage.

Matenge, B. 2012. University of Cape Town. Manuscript, Psychology Department, University of Cape Town, Cape Town. Retrieved June 13, 2019, from http://www.psychology.uct.ac.za/sites /default/files/image_tool/images/117/ Batetshi.Matenge.pdf

Mcguire, B. K., Crowe, T. K., Law, M., \& Vanleit, B. 2004. Mothers of Children with Disabilities: Occupational Concerns and Solutions. OTJR: Occupation, Participation and Health, 24(2), 54-63. doi:10.1177/153944920402400203

Menkes, J. H. 2006. Child neurology. Philadelphia: Lippincott Williams \& Wilkins.

Misquiatti, A. R., Brito, M. C., Ferreira, F. T., \& Júnior, F. B. 2015. Sobrecarga familiar e crianças com transtornos do espectro do autismo: Perspectiva dos cuidadores. Revista CEFAC,17(1), 192-200. doi:10.1590/19820216201520413

Mulhall, A. 2003. In the field: Notes on observation in qualitative research. Journal of Advanced Nursing,41(3), 306-313. doi:10.1046/j.13652648.2003.02514.x

Risser, R., Forward, S., Steg, L., Martincigh, L., \& Schmeidler, K. 2014, March 11. State of the art International Publishing AG. doi:10.1007/978-3-319-59066-0

Shu, B. 2009. Quality of life of family caregivers of children with autism. Autism, 13(1), 81-91. doi:10.1177/1362361307098517 report on Life Quality assessment in the field of transport and mobility. Retrieved June 13, 2019, from https://www.researchgate.net/publicat ion/238071557_State_of_the_art_rep ort_on_Life_Quality_assessment_in_t he_field_of_transport_and_mobility.

Rosita, R., Soepardi, J., H., Sitohang, V., Brahim, R., S., Pangribowo, S. 2010. Profil Kesehatan Indonesia Tahun 2009. Retrieved June 13, 2019, from http://depkes.go.id/folder/view/01/str ucture-publikasi-pusdatin-profilkesehatan.html

Ruiz-Robledillo, N., Bellosta-Batalla, M., \& Moya-Albiol, L. 2015. Lower cardiovascular reactivity to acute stress in informal caregivers of people with autism spectrum disorder than in non-caregivers: Implications for health outcomes. International Journal of Psychophysiology,98(1), 143-150. doi:10.1016/j.ijpsycho.2015.07.011

Schalock, R. L. 2004. The concept of quality of life: What we know and do not know. Journal of Intellectual Disability Research,48(3), 203-216. doi:10.1111/j.13652788.2003.00558.x

Schalock, R. R., Verdugo, M. A., \& Gomez, L. E. 2017. Translating the Quality of Life Concept into Practice. In Handbook of Positive Psychology in Intellectual and Developmental Disabilities(pp. 115-126). Bazel, Switzerland: Springer Stuart, M., \& Mcgrew, J. H. 2009. Caregiver burden after receiving a diagnosis of an autism spectrum disorder. Research in Autism Spectrum Disorders,3(1), 86-97. doi:10.1016/j.rasd.2008.04.006 
Theofilou, P. 2013. Quality of Life: Definition and Measurement. Europe's Journal of Psychology,9(1), 150-162. doi:10.5964/ejop.v9i1.337

Thorne, S. 2000. Data analysis in qualitative research. Evidence-Based Nursing,3(3), 68-70. doi:10.1136/ebn.3.3.68

Tung, L., Huang, C., Tseng, M., Yen, H., Tsai, Y., Lin, Y., \& Chen, K. 2014. Correlates of health-related quality of life and the perception of its importance in caregivers of children with autism. Research in Autism Spectrum Disorders,8(9), 1235-1242. doi:10.1016/j.rasd.2014.06.010

Tung, L., Huang, C., Tseng, M., Yen, H., Tsai, Y., Lin, Y., \& Chen, K. 2014. Correlates of health-related quality of life and the perception of its importance in caregivers of children with autism. Research in Autism Spectrum Disorders,8(9), 1235-1242. doi:10.1016/j.rasd.2014.06.010

W. 1997, January 01. WHOQOL : Measuring quality of life. Retrieved June 13, 2019, from https://apps.who.int/iris/handle/10665 163482

Woodgate, R. L., Ateah, C., \& Secco, L. 2008. Living in a World of Our Own: The Experience of Parents Who Have a Child With Autism. Qualitative Health Research,18(8), 1075-1083. doi:10.1177/1049732308320112

Yin, R. K. 2016. Qualitative research from start to finish. New York: Guilford Press. 